\title{
Picobia polonica sp. n. (Acari: Prostigmata: Syringophilidae), a new species of quill mite from the domestic hen, Gallus gallus domesticus (Aves: Phasianidae)
}

\author{
Maciej Skoracki $^{1}$, Wojciech Magowski ${ }^{2}$ and Jacek Dabert ${ }^{1}$ \\ ${ }^{1}$ Department of Animal Morphology, A. Mickiewicz University, 28 Czerwca 1956/198, 61-485 Poznań, Poland; \\ ${ }^{2}$ Department of Animal Taxonomy and Ecology, A. Mickiewicz University, Szamarzewskiego 91A, 60-569 Poznań, Poland
}

Key words: Acari, Syringophilidae, ectoparasites, physogastry, Gallus gallus domesticus

\begin{abstract}
Female, physogastric female and male of Picobia polonica sp. n. collected from the domestic hen Gallus gallus domesticus (L.) in Poland are described and the phenomenon of physogastry in this and related species is briefly discussed. Picobia polonica is similar to Picobia khulkhshani (Kivganov et Sharafat, 1995). These two species can be distinguished by the following characters: P. polonica: chelicerae dentate, each with three minute teeth; setae $g 1$ and $p g 2$ subequal in length; ratio pg1:pg2, 3:1. P. khulkhshani: chelicerae edentate; setae $g 1$ twice shorter than $p g 2$; ratio $p g 1: p g 2,1.6: 1$.
\end{abstract}

The syringophilid mites live and reproduce inside the quills of the remiges, restrices, coverts and body feathers of birds. They feed on soft tissue fluids of their hosts by piercing the calamus wall with their long, stylettiform chelicerae (Kethley 1971, Casto 1974). Within the ecologically diverse family Syringophilidae, a number of species have been described in association with eighteen families of birds (Kethley 1970, Kethley and Johnston 1975, Casto 1977, Philips and Norton 1978). Most syringophilids appear to be host specific. Previously, only Syringophilus bipectinatus Heller, 1880 was known from Gallus gallus L. (Kethley 1970).

In this paper we describe the female, physogastric female and male of a new species of quill mite found in the body feathers of one specimen of the domestic hen Gallus gallus domesticus in Poland.

\section{MATERIALS AND METHODS}

Mites were collected from quills of body feathers of a domestic hen and stored in $70 \%$ ethanol. Subsequently, they were mounted in a polyvinylolactophenol medium in microscopic slides and studied with an Olympus BH 2 microscope equipped with the differential interference contrast (Nomarski) optics. The terminology used follows Kethley (1970, 1973). All measurements are given in micrometres $(\mu \mathrm{m})$; the ranges represent 8 non-physogastric female, 7 physogastric female and 3 male specimens.

\section{RESULTS}

Picobia polonica sp. $\mathrm{n}$.

Figs. 1-9

Non-physogastric female, holotype (7 paratypes in parentheses)

Figs. 1-5
Gnathosoma. Hypostomal apex with one pair of small protuberances (Figs. 3, 4). Chelicerae dentate, each with three small teeth. Peritremes M-shaped (Fig. 5), each lateral branch with 3-6 chambers, each longitudinal branch with 9-11 chambers. Stylophore 190 (200) long, rounded posteriorly. Gnathosoma with punctate ornament ventrally.

Idiosoma. Propodosomal plate divided longitudinally. Setae $v i$, ve, sci and $l 1$ located on the plate. Setae $d 3$ closer to $l 2$ than to $l 3$ or equidistant between $l 2$ and l3. Dorsal setae vi, ve and sci strongly ornamented, other idiosomal setae weakly ornamented. Hysterosomal and pygidial plates absent. Genital series consisting of one pair of setae, anal series of two pairs of setae; paragenital series with three pairs of setae.

Legs. Legs I and II thicker than III and IV. Dorsal and lateral setae of legs ornamented. Mesial coxal apodemes of legs I (MCA1) parallel, not fused with MCA2. MCA1 punctate. Coxae III and IV well developed. Cuticular striations as in Figs. 1, 2.

Lengths of setae. $v i$ : (52-59); ve: (130-143); sci: 170 (170-180); sce: (250-265); l1: (255-265); l2: (230-255); l3: 140 (140-170); l4: 460 (510-540); l5: (340-380); d1: (270-280); d3: (190-220); d4: 66 (60-70); d5: 48 (4552); g1: 71 (75-80); g2: (25); a: (12); pg1: 204 (220230); pg2: 65 (63-80); pg3: 235 (245-290); 1a: 100 (110-120); 3a: 100 (95-110); 1b: 50 (50-60); $2 b$ : (135150); 3b: 25 (30); 4b: (30); 1c: (45-70); 3c: (130-150); $4 c$ : (130); pmc: 32 (30-40); sc3: 20 (25-30); sc4: (20$30)$.

Distances between setal bases. $v i$-vi: 55 (70-75); veve: 55 (70); vi-ve: 10 (10); ve-sci: 40 (40); sci-l1: 90 (90-100); l1-l2: 70 (85); ll-ll: 105 (120-125); d1-d1: 40 (40-50); l2-l2: 136 (150-160); l3-l3: 90 (90-110); d3-d3: 

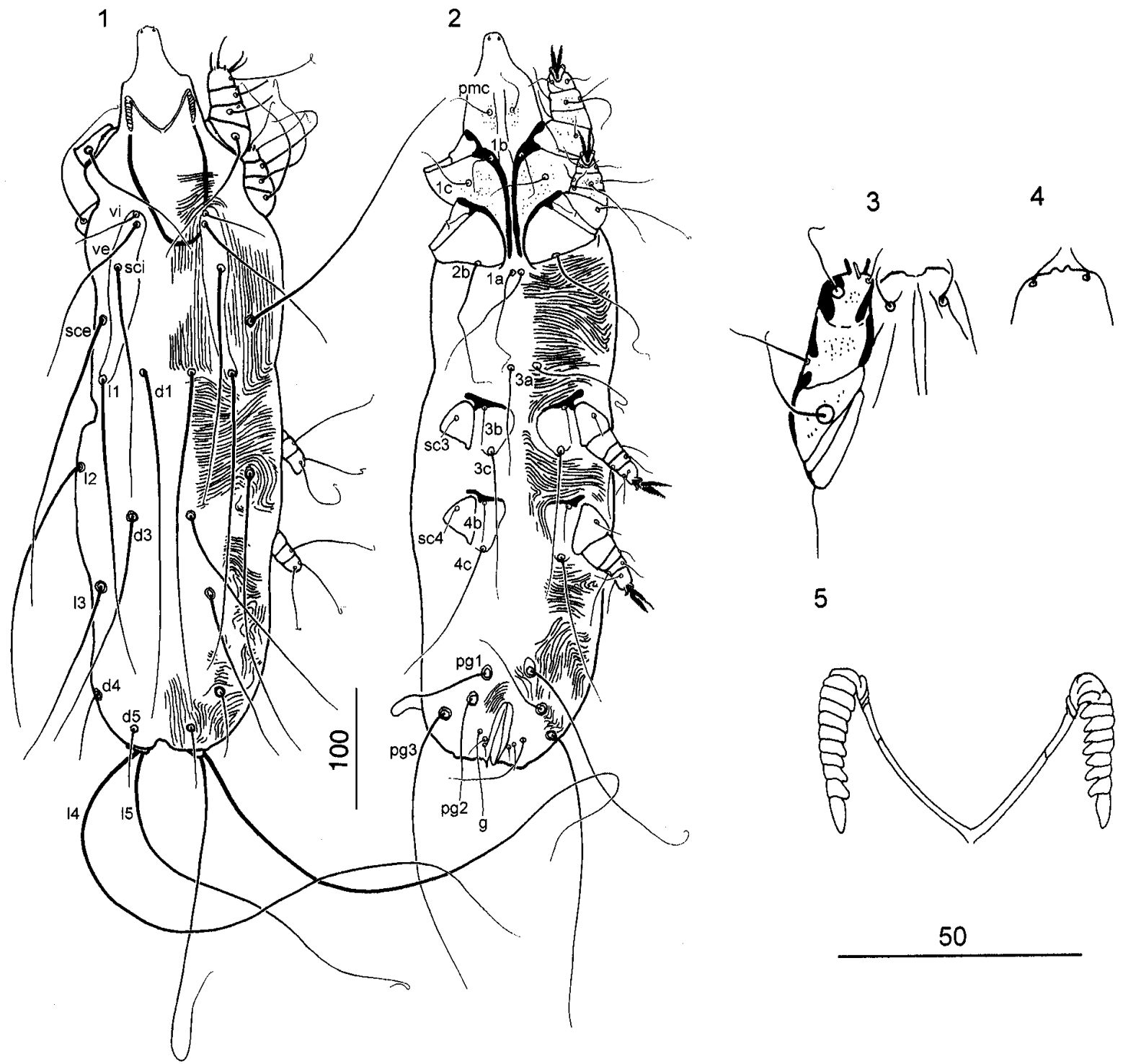

5

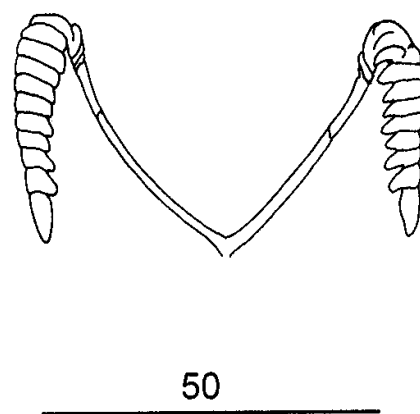

Figs. 1-5. Picobia polonica sp. n., female (non-physogastric). Fig. 1. Dorsal view. Fig. 2. Ventral view. Fig. 3. Gnathosoma, ventral view. Fig. 4. Hypostomal apex, dorsal view. Fig. 5. Peritreme. Scale bars in $\mu \mathrm{m}$.

(40-45); l2-d3: (65-80); d3-l3: (70-80); l3-d4: 90 (90$100)$; $d 4-d 5: 45$ (45-50); d4-d4: 100 (120); d5-d5: 40 (50); pmc-1b: 35 (35-40); 1c-1c: 65 (70-80); $2 b-2 b: 65$ (60-80); la-3a: 75 (70-90); pgl-pg1: 30 (35); pg2-pg2: 60 (65); pg3-pg3: 95 (105); pg1-pg2: 35 (35); pg2-pg3: $20(20-25)$.

\section{Physogastric female $(n=7)$}

Figs. 6, 7

Morphology of gnathosoma, idiosoma and legs as in normal form, except for total length being 1215-1231 and shape of idiosoma campanulliform in outline, with opisthosoma strongly distended posteriad of legs IV. Lengths of idiosomal setae as in normal form. Cuticular striations as in Figs. 6, 7. Coxal fields of legs I and II contiguous, longitudinal interval between coxal fields III and IV only slightly shorter than that between fields II and III.

Distances between setal bases. vi-vi: 88 ; ve-ve: 88 ; sci-sci: 143 ; sce-sce: $250 ;$ vi-ve: $10-12 ;$ vi-sci: 62 ; visce: 119 ; vi-ll: 155; l1-l2: 293; l1-d1: $60 ; d 1-d 1$ : 52; l2l2: 226; l3-l3: 271-274; d3-d3: 52-55; l2-l3: 186; l2-d3: 112; l3-d4: 214; d4-d5: 74; d4-d4: 219; d5-d5: 95; l1d4: 693; 1a-1a: 7; 1a-3a: 171; 3a-3a: 40; 3b-3b: 119; 4b-4b: 145; 3a-3b: 131; 3b-4b: 193; la-pg1: 743; pg1pg1: 33-45; pg2-pg2: 90; pg3-pg3: 136; pg1-pg2: 38; pg2-pg3: 64. 


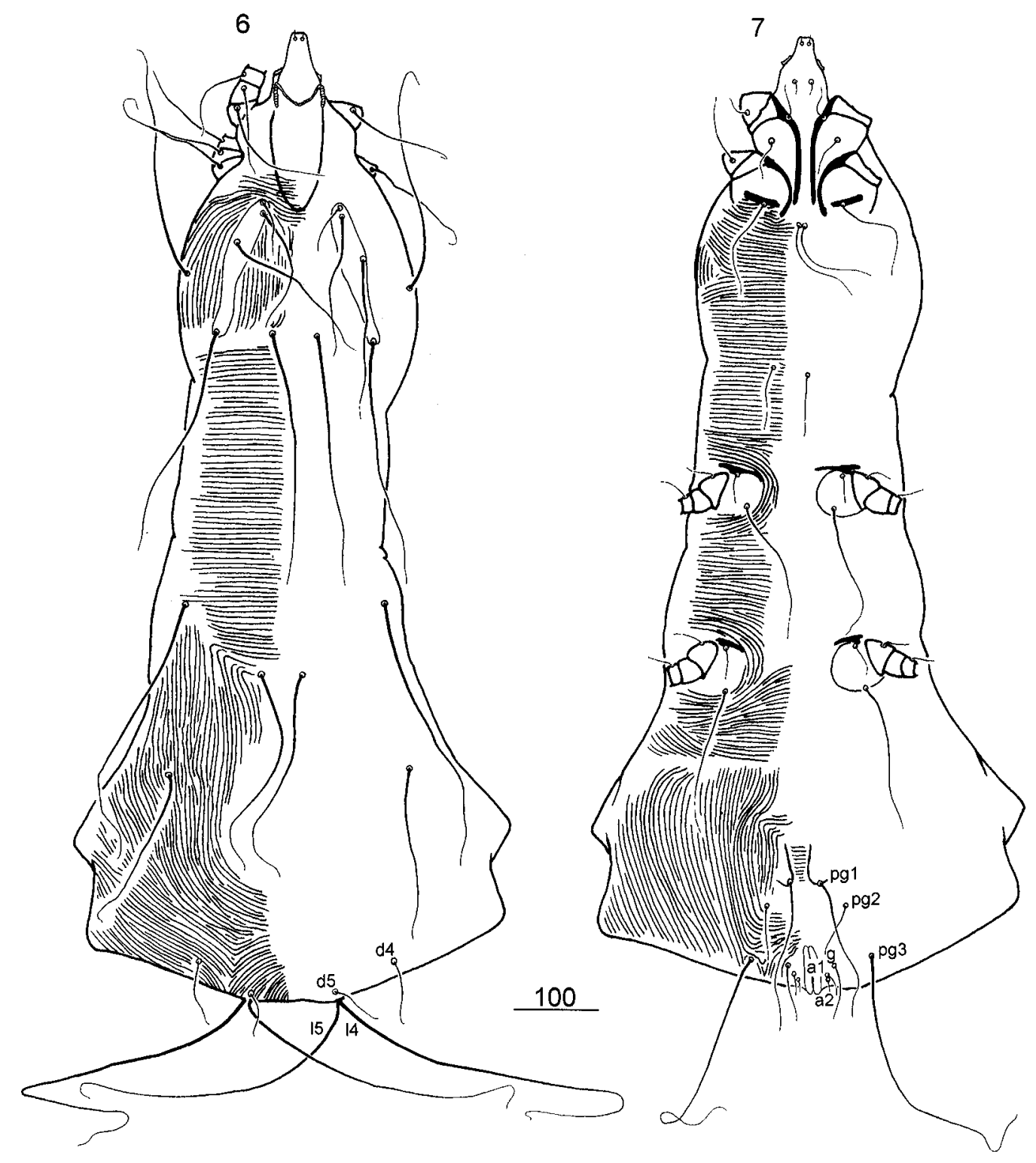

Figs. 6, 7. Picobia polonica sp. n., female (physogastric). Fig. 6. Dorsal view. Fig. 7. Ventral view. Scale bar in $\mu \mathrm{m}$.

Male $(\mathrm{n}=3)$

Total length 431-435.

Gnathosoma. Apical margin of hypostome not ornamented. Chelicerae dentate. Stylophore 94-96 long, rounded posteriorly. Peritreme M-shaped, each lateral branch with 3-5 chambers, each longitudinal branch with 9-11 chambers.

Idiosoma. Propodosomal plate poorly developed, anterior and posterior margins weakly defined. Setal pattern of propodosomal region with six pairs of setae arranged 2-1-1-2. Hysterosomal plate present, bearing setae $d 3$ and $l 3$. Setae $d 3$ located closer to $l 3$ than to $l 2$. Each of anal and genital setal series represented by two pairs. Paragenital series with two pairs of setae. Two plates ventrally on opisthosoma near setae pg1. MCA1 parallel, not fused with MCA2. Cuticular striations as in Figs. 8, 9. Legs as in female.

Length of setae. $v i$ : $38-40 ;$ ve: 73-86; sce: 121-143; l1: 120-150; l2: 98-102; l3: 9-12; l4: 272-309; $d 1$ : 125; d3: 10-14; d4: 12-14; $a 1$ and $a 2: 2 ; g 1$ and $g 2: 4 ; a o 1$ and ao2: 2 ; pmc: 17; 1a: 54; 3a: 46; 1b: 25- 29; $2 b: 75-$ 78; 3b: 20-22; 4b: 16; 1c: 33-46; 3c: 70; 4c: 64-66; sc3: 14-16; sc4: 16; pg1: 95-106; pg2: 57-62.

Distances between setal bases. vi-vi: 44; ve-ve: 44; vi-ve: 6 ; vi-sci: 38 ; ve-sci: 36 ; sci-sci: 75 ; vi-sce: 64 ; scisce: 29; vi-l1: 94; l2-l2: 98; d3-d3: 36; l3-l3: 61; l1-l2: 59; 12-d3: 52; 1a-1a: 3; 1a-3a: 66; 3a-3a: 11; 1b-1b: 11; pg1-pg1: 22; pg2-pg2: 35; pg1-pg2: 52; sce-l1: 44; sce- 


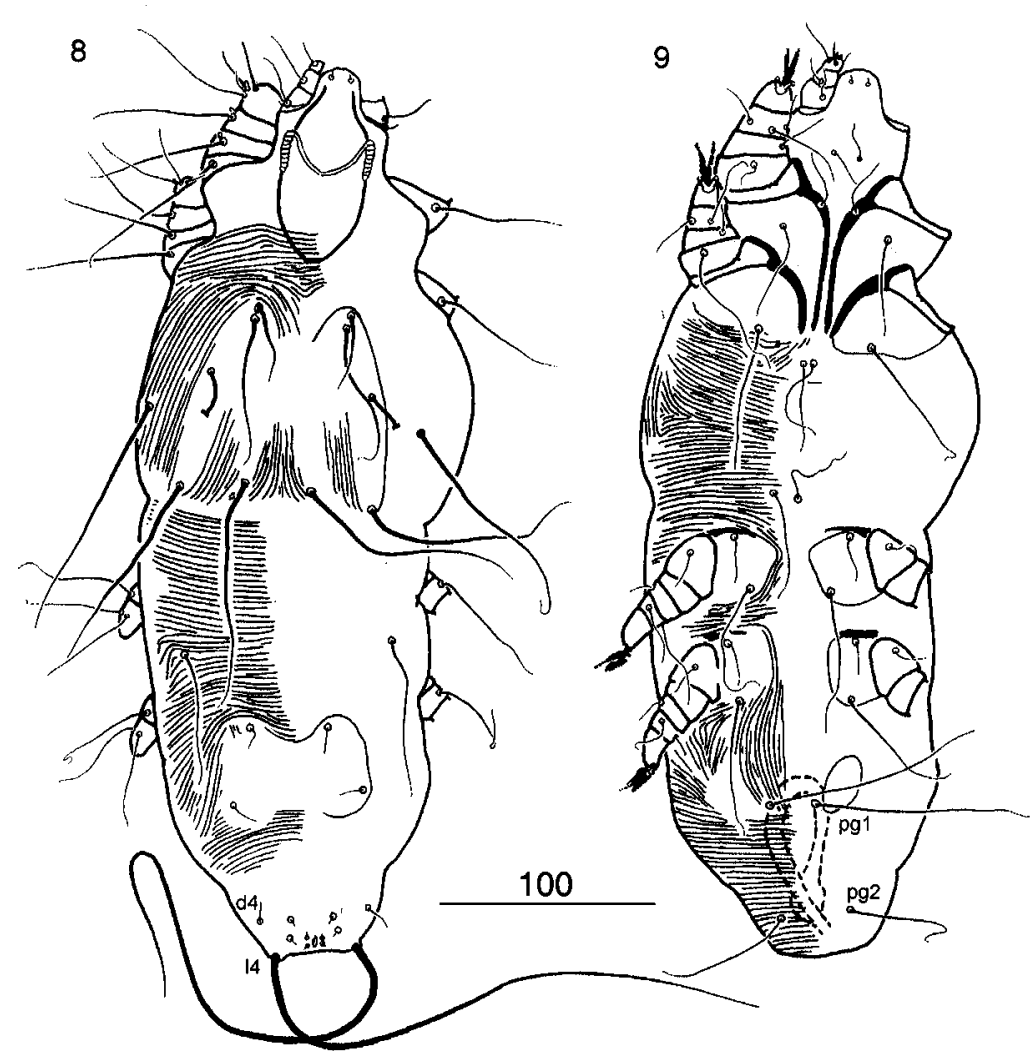

Figs. 8, 9. Picobia polonica sp. n., male. Fig. 8. Dorsal view. Fig. 9. Ventral view. Scale bar in $\mu \mathrm{m}$.

sce: $127 ; l 1-d 1: 30 ; d 1-d 1: 30 ; d 4-d 4: 52 ; g 1-g 1: 21 ; g 2-$ g2: $23 ; g 1-g 2: 7-9 ; l 1-d 4: 189 ; d 3-13: 33 ; 13-d 4: 57 ; 3 a-$ 3b: 30; 3b-4b: 49; la-pg1: 209.

T y p e h o s t: Gallus gallus domesticus (L., 1758) (Aves: Phasianidae).

S i t e : Quills of body feathers.

$\mathrm{T}$ y $\mathrm{p}$ e 1 o c a 1 i t y : Zasutowo near Wrzesnia; Wielkopolska, Poland; 20.04.1999, coll. Jerzy Dabert.

$\mathrm{T}$ y $\mathrm{p}$ e $\mathrm{s} p$ e c i m e $\mathrm{n} \mathrm{s}$ : Holotype female, 8 nonphysogastric female paratypes, 7 physogastric female paratypes, 3 male paratypes, 3 nymphal paratypes and 2 eggs.

De p o s ition of materia 1 : Holotype (No. S-9.1.1.), 3 non-physogastric female, 4 physogastric female, 1 male and 1 nymphal paratypes (Nos. S-9.1.2.-S-9.1.10.) deposited in the Department of Animal Morphology, A. Mickiewicz University, Poznań, Poland; 2 nonphysogastric female, 2 physogastric female, 1 male and 1 nymphal paratypes (Nos. S-9.1.11.-S-9.1.17) deposited in the Zoological Museum of the Hamburg University, Hamburg, Germany; 2 non-physogastric female, 2 physogastric female, 1 male and 1 nymphal paratypes (Nos. S-9.1.18.-S-9.1.24) deposited in the U.S. National Museum, Insect and Mite Collection, Beltsville, Maryland, USA; 1 non-physogastric female and 1 physogastric female paratypes (Nos. S-9.1.25, S-9.1.26) deposited in the Canadian National Collection, Ottawa, Ontario, Canada.

$\mathrm{E} t \mathrm{y} \mathrm{m}$ ol o $\mathrm{g} \mathrm{y}$ : The new species is named after the country of origin.

\section{Diagnosis}

Adult females of Picobia polonica are similar to Picobia khulkhshani (Kivganov et Sharafat, 1995) described from a nest of the rock dove Columba livia (Kivganov and Sharafat 1995) in the following characters: propodosomal plate divided, setae vi, ve, sci and $l 1$ located on the plate; stylophore rounded posteriorly; setal pattern of propodosomal region 2-1-12. Hysterosomal plate absent; setae $l 4$ and $l 5$ strongly attenuate. The new species can be distinguished from $P$. khulkhshani by the following characters: P. polonica: chelicerae dentate, each with three minute teeth; setae $g 1$ and $p g 2$ subequal in length; ratio $p g 1: p g 2,3: 1 ; P$. khulkhshani: chelicerae edentate; setae $g 1$ twice shorter than $p g 2$; ratio $p g 1: p g 2,1.6: 1$.

\section{DISCUSSION}

The order Galliformes is known to support numerous genera of syringophilid mites (Kethley 1973, Casto 1980, Chirov and Kravtsova 1995). Picobia polonica and Syringophilus bipectinatus, both collected from Gallus gallus domesticus, represent a rare case in which multiple syringophilid genera are associated with a single host species.

The term physogastry is used to describe a physiological state of enlargement of a female body associated 
with intensive feeding and reproduction. This phenomenon is known to commonly occur in the prostigmatic mite group Heterostigmata (Kaliszewski et. al. 1995) as well as in some members of the Gamasida; however, its potential range of occurrence among taxa of Acari may be wider than previously suspected.

Although some apparently physogastric forms have already been described in the Syringophilidae, they have not been formally referred to as such. Physogastric females are still unknown in the subfamily Syringophilinae and there are only a few records of such forms in the Picobiinae. Fritsch (1958) described Syringophilus dryobates (=Picobia dryobates sensu Kethley, 1970) based on the apparently physogastric form. Casto (1977) mentioned "gigantic" forms in the description of Calamincola lobatus (Casto, 1977). None of those authors, however, used the term physogastry, and they apparently were not aware that they might have been dealing with a different biological form.
The evolutionary meaning of physogastry is an expression of a trend toward increased egg production (and/or retention) per single mother. It remains obscure whether the existence of both non-physogastric and physogastric females in a single population of $P$. polonica provides an adaptive advantage or represents temporal developmental variations between individuals. Future observations on the biology of syringophilids are necessary to find an answer to this question. Making such observations continues to be a difficult task, as satisfactory methods of studying living quill mites have yet to be developed.

Acknowledgements. We thank Drs. Ronald Ochoa, Systematic Entomology Laboratory, USDA, and Ethan Kane, University of Maryland - College Park, USA for their comments on the manuscript and helpful suggestions. We also thank Mr. Jerzy Dabert for supplying us with the mite material for our study.

\section{REFERENCES}

CASTO S.D. 1974: Quill wall thickness and feeding of Syringophiloidus minor (Berlese) (Acarina: Syringophilidae). Ann. Entomol. Soc. Am. 67: 824.

CASTO S.D. 1977: Cuculiphilus lobatus gen. n., sp. n. representing a new subfamily of quill mites (Acarina: Syringophilidae) from the Groove-billed Ani, Crotophaga sulcirostris (Cuculiformes: Cuculidae). Southw. Nat. 22: 169-176.

CASTO S.D. 1980: A new genus of syringophilid mites from galliform birds in Texas. Tex. J. Sci. 32: 233-240.

CHIROV P.A., KRAVTSOVA N.T. 1995: A new genus and new species of mites of the family Syringophilidae. Parazitologiya 29: 370-379. (In Russian.)

FRITSCH W. 1958: Die Milbengattung Syringophilus Heller, 1880. Zool. Jahrb. 86: 227-244.

KALISZEWSKI M., ATHIAS-BINCHE F., LINDQUIST E.E. 1995: Parasitism and parasitoism in Tarsonemina (Acari: Heterostigmata) and evolutionary considerations. Adv. Parasitol. 35: 335-367.
KETHLEY J.B. 1970: A revision of the family Syringophilidae (Prostigmata: Acarina). Contrib. Am. Entomol. Inst. 5 (6): 1-76.

KETHLEY J.B. 1971: Population regulation in quill mites (Acarina: Syringophilidae). Ecology 52: 1113-1118.

KETHLEY J.B. 1973: A new genus and species of quill mites (Acarina: Syringophilidae) from Colinus virginianus (Galliformes: Phasianidae) with notes on developmental chaetotaxy. Fieldiana Zool. 65: 1-8.

KETHLEY J.B., JOHNSTON D.E. 1975: Resource tracking in birds and mammalian ectoparasites. Ann. Entomol. Soc. Am. 9: 229-236.

KIVGANOV D.A., SHARAFAT G.S. 1995: Review of the family Syringophilidae (Acari) with the description of new genera and species. Zool. Zh. 74 (4): 82-91. (In Russian.)

PHILIPS J.R., NORTON R.A. 1978: Bubophilus ascalaphus gen. et sp. n. (Acarina: Syringophilidae) from the quills of Great Horned Owl (Bubo virginianus). J. Parasitol. 64: 900-904.

Accepted 9 November 2000 